\title{
Еще один миф о происхождении езидов
}

\author{
Abstract
}

\section{Another Ethnogenetic Myth of the Yezidis}

The article is an attempt of the analysis of the ethnogenetic myths preserved in the Yezidi folklore. A special focus is made on the third, previously unknown version of the Yezidi origin. The latter was found in a text written down in the 40s of the last century in Armenia. It is particularly interesting that the legend reveals an obvious parallel with one the Shahnameh's story lines. Among the specific features of the text is the unique use of the term "Ezdistan".

Keywords: Ездистан Yezidis, ethnogenetic myths, Kurds in Shahnameh, Ezdistan

Ключевые слова: Езиды, этногенетические мифы, курды в «Шахнамэ»

Езидизм, ${ }^{1}$ будучи традицией синкретической, вобрал в себя и удивительным образом совместил целый ряд порой противоречащих друг другу элементов из множества религий, в том числе принадлежащих к разным очагам. Сосуществование таких противоречивых элементов - лежащих ли в основе традиции, находящихся ли на маргинальных ее уровнях - объясняется отсутствием в этом религиозном учении догмы в строгом смысле этого слова.

Одним из ярких примеров вышесказанного является наличие в езидизме двух легенд о происхождении народа езидов. Ссылка на одну их них, более распространенную, имеется в устном варианте езидской космогонии Qawlē àfrīnā dinyāye $:^{2}$

Великий Бог сказал ангелам: «Я создал Адама и Еву, и их я сделаю людьми. От сути Адама возникнет Шахд бин Сафар, который породит на земле народ, от которого появится позднее народ Азраила, т.е. Малак-Тавуса, который народ езидов».

${ }^{1}$ О езидизме в целом см. J. Guest, The Yezidis. A Study in Survival, New York 1987; Ph. Kreyenbroek, Yezidism - Its Background, Observances and Textual Tradition, New York 1995; G. Asatrian, V. Arakelova, The Religion of the Peacock Angel: The Yezidis and their Spirit World, Durham 2014.

${ }^{2}$ Ph. Kreyenbroek, op. cit., pp. 182-192. 
Данный стих относит нас к популярной версии происхождения езидов исключительно от Адама, а не от его связи с Евой, как в случае с остальным человечеством. Предание это, в основе которого лежит, скорее всего, апокрифическая гностическая легенда, повествует о споре Адама и Евы о главенствующей роли в порождении детей. Чтобы доказать, что притязания женщины на эту роль безосновательны, Адам предлагает поместить отдельно в двух кувшинах свое семя и семя Евы и подождать до созревания плода. В результате, по истечении срока в кувшине Евы находят червей, скорпионов и разных гадов, а в кувшине с семенем Адама - луноликого мальчика, которого называют Шахид бин Джарр (Š̄̄hid bin Jarr, т.е. араб. «Свидетель, сын кувшина»). В тексте «Писания» в обеих версиях - курдской и арабской - Šahr bin Safar, что следует, скорее всего, рассматривать как искаженное (с буквой ре вместо дал) Šāhid bin Safar. Патроним же Safar (букв. араб. «желтый»), по всей видимости, намек на јarr «кувшин», сделанный из глины желтого цвета. В дальнейшем, согласно легенде, от брака сына Адама и райской гурии происходит племя езидов. Адам, будучи истинным езидом, передает свою религию Шахиду, а тот - своим потомкам. ${ }^{3}$ Искаженный Библейский сюжет, пусть и в апокрифическом, гностическом прочтении, ${ }^{4}$ однозначно указывает на авраамические истоки данной легенды.

Вторая легенда о происхождении езидского народа связна с образом P̄̄rā Fāt - легендарной праматери езидов и богине-покровительницы рожениц и младенцев.

Пира Фат ${ }^{5}$ - своего рода праматерь езидов, ибо она, спасая семя езидского народа от уничтожении, берегла его у себя на протяжении семисот, а по другой версии - семи тысяч лет. От этого семени и произошел езидский народ ${ }^{6}-$ повествует отголосок альтернативной легенды о происхождении народа езидов.

Практически не вызывает сомнения принадлежность данной легенды к индоиранскому религиозному очагу с типичной для него мифологемой сохранения семени и связи его с жидкой средой. ${ }^{7}$

По преданию, семя было передано на хранение Пира Фат Шейхом Абу Бакром (Шехобакр) - воплощением ангела Микаила, одного из аватар Малак Тауса. Более подробных деталей этой легенды не сохранилось, но в гимне,

${ }^{3}$ См. N. Sioufi, Notice sur la sect des yézidis, "Journal Asiatique" 1882, vol. 19, pp. 259-260; S. Giamil, Monte Singar: Storia di un Popolo Ignoto, Rome 1900, pp. 17-18; R. Lescot, Enquête sur les Yesidis de Syrie et du Djebel Sinjār, Beyrut 1938, p. 59; G. Asatrian, V. Arakelova, The Religion..., pp. 14-15.

${ }^{4}$ См. в частности, E. Spät, Shahid bin Jarr, Forefather of the Yezidis and the Gnostic Seed of Seth, "Iran and the Caucasus" 2002, vol. 6, no. 1-2.

${ }^{5}$ См. о ней подробно G. Asatrian, Foremother of the Yezidis, [in:] Religious Texts in Iranian Languages, eds. F. Vahman, C.V. Pedersen, Copenhagen 2007.

${ }^{6}$ A. Tamoyan, Menk' ezdi enk', Yerevan 2001, p. 152.

${ }^{7}$ Cр., например, семя Гайомарта, сохранившееся на протяжении сорока лет в поглотившей его Спандармат (земле) и дальнейшее произрастание из него Мартйи и Мартйанака; семя Архонтов в манихействе, упавшее с неба на землю и породившее растительный мир и т.д.; семя Зороастра, хранившееся в озерое Кансаойа; семя Шивы, упавшее с неба и породившее богов и т.д. 
посвященном Шехобакру (Qawlē Šēxōbak'r), имеется намек на нее - пожалуй, единственное упоминание легенды в устной религиозной литературе.

P'ādšāyē min vē yakē dilšāya,

Faqīrak šāndīya tavakā harharē, āvak ānyīya;

Nāv wē dānīya šarāv, ti'un, A'ynil-bayzāya;

Aw řǒža, av řōža, mijlisā mērē ēzdī pē būya āvāya. ${ }^{8}$

Бог (букв. «царь») мой оттого радостен,

[Что] послал однажды факира одного 9

в седьмую сферу неба; [тот] принес жидкость;

В ней было: вино, мука и [вода из] Белого источника;

В тот день, в этот день община езидов появилась. ${ }^{10}$

«Жидкость» эта состояла из четырех элементов, которые, очевидно, метафорически обозначены в приведенном отрывке: вино - огонь, мука земля и вода (из священного источника). Отсутствует воздух, но чуть ниже, в том же гимне, прямо указываются все четыре элемента.

P'ādšāyē min̄̄ jabāra,

Ži duřē farq (думается, должно быть xalq) kirna čāra (должно быть cāa)a):

Bāya, āva, āxa ū nāra.

Бог (букв. «царь») мой могущественен,

Из перла сотворил жидкость (состоящую из):

Воздуха (букв. «ветра»), воды, земли и огня.

Интересно, что в данном случае антропогонический миф накладывается на саму символику мироздания - перл: ${ }^{11}$ «жидкость», «семя ездского народа» выступает как своего рода артефакт первозданной жемчужины, становясь тем самым и общим антропогоническим мифом, распространяющимся на все человечество, а не только на езидов, и элементом космогонии.

Эта же версия происхождения езидов косвенно отражена и в следующем отрывке из кавла Шейха Арабаги Антузи, который представляет собой образец религиозной полемики с представителями других конфессий. Здесь в небольшом пассаже четко видно противостояние двух антропогонических мифов:

${ }^{8}$ O. Celil, C. Celil, Zargotina Kurda, Yerevan 1978, p. 381.

9 Вероятно, Шехобакр (V.A.).

10 Третья строчка данного отрывка с учетом эмендации должна быть интерпретирована

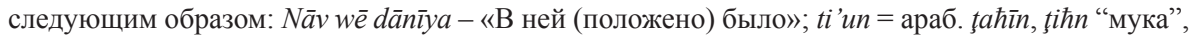
A'ynil-bayzā = араб. a 'yn-ul-bayđa "белый источник" (имеется в виду Канийа-сыпи (Kānīya $\bar{a} s p \bar{\imath}-$ букв. «Белый источник») - священный источник в Лалеше, т.е., разумеется, вода из этого источника (G. Asatrian, V. Arakelova, The Religion..., pp. 73-74).

11 И «Черное писание» езидов (М. Bittner, Die heilige Bücher der Jeziden oder Teufelsanbeter (kurdisch und arabisch), Vienna 1913, §§ 10-13), и устный вариант езидской космогонии - Qawlē $\bar{a}$ rīna a dinyāyē (Ph. Kreyenbroek, op. cit., pp. 182-192) однозначно указывают на жемчужину (dir, араб. durr) как на основу мироздания, первоначальный источник, из которого создано все сущее земля, растения, небесные светила, явления природы и, как указывает анализируемый текст, само семя, породившее первочеловека/первого езида. 


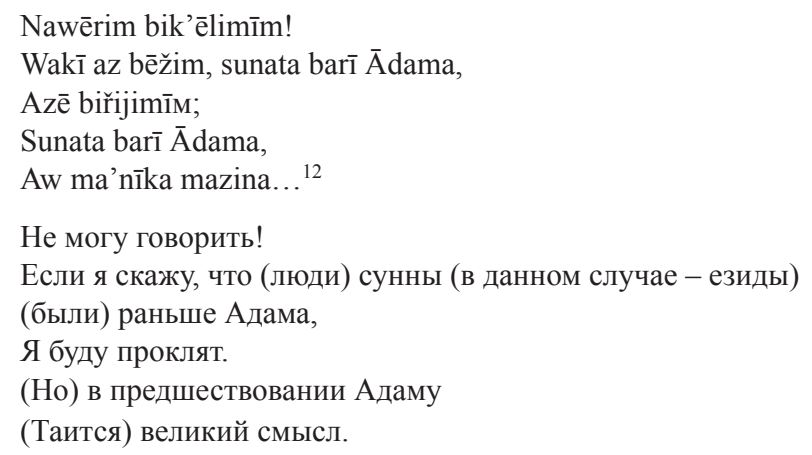

Очевидно, что создатель данного кавла был знаком с легендой о происхождении езидов от Адама, и потому его «смущает» утверждение о существовании езидов «раньше Адама». Тем не менее, он эту идею озвучивает и сообщает, что в «предшествовании Адаму» сокрыта некая тайна, «великий смысл». Налицо - попытка «примирить» существование в традиции двух антропогонических мифов, подводящая таинственную подоплеку под менее популярную, но однозначно более архаичную версию с семенем Пира Фат.

Несмотря на маргинальный характер легенды, само понятие семени Пира Фат актуально и присутствует в ряде важных молитвенных формул. Сопровождая женщину при родах, принято пожелать ей содействия Пира Фат, а если быть более точным - ее семени: Ĉ̄āā Pirā Fāt bē hawārā ta! «Пусть семя Пира Фат содействует тебе!», ${ }^{13}$ что указывает на рождение истинного представителя общины, возводящего свой род к первоначальному семени езидского народа, хранительницей которого, согласно традиции, и была Пира Фат. ${ }^{14}$

Поразительно, но, наряду с упомянутыми выше двумя антропогоническими мифами, в фольклоре езидов зафиксирована еще одна, третья, доселе неизвестная версия происхождения этого народа. Она обнаружена нами в тексте, записанном в 40-х года прошлого века в Армении езидским пандитом Амине Авдалом. Текст был записан у Ахмаде Чоло (Ahmade Čolo) из деревни Алагяз Аштаракского района. Ахмаде Чоло - известный сказитель, выходец из восточных регионов Османской Империи (исторической Западной Армении), переселившийся на территорию Восточной Армении в результате геноцида немусульманских народов Османской империи. Ахмаде Чоло слыл авторитетным знатоком и интерпретатором езидского устного народного творчества. Рассказанная им легенда гласит:

У некоего неправедного царя на плечах выросли два змея. Чтобы оградить себя от их опасного и вредоносного присутствия, царь обратился за советом к шейхам. Те

12 O. Celil, C. Celil, Zargotina Kurda, vol. 2. Moscow 1978, pp. 5-6.

13 Слово $\hat{c} \bar{a} r$ в данной формуле означает «семя» - значение, развившееся из первичной семантики этой формы - «средство, возможность» - через промежуточные значения «лекарство, жидкость» (ср. ср.-перс. čārak н.-перс. čāra) (G. Asatrian, Foremother of the Yezidis, p. 324).

14 Ibidem, pp. 324-325. 
посоветовали ему ежедневно кормить змей человеческим мозгом. Таким образом, по приказу царя, палачи ежедневно убивали молодого мужчину из жителей страны и удовлетворяли голод змей. Но вскоре палачам стало жалко молодых людей и они начали убивать [вместо людей] овец и кормить их мозгом змей. Спасенные молодые мужчины нашли убежище в горах Ездистана, где из их потомков и появился в дальнейшем народ езидов. Скрываясь в горах, они начали борьбу с тираном и в конце концов одолели его. ${ }^{15}$

Данная легенда, помимо того, что является, по сути, третьей засвидетельствованной в традиции мифологической версией происхождения езидов, представляет интерес еще по ряду параметров.

Прежде всего, в легенде прослеживается очевидная параллель с одной из сюжетных линий «Шахнамэ», а именно с историей Заххака - исполненного властолюбия и нечестивых желаний правителя. Соблазнившись обещанием безграничной власти, Заххак вступает в союз с Ахриманом, убивает с его помощью своего отца и занимает его престол. Ахриман, обернувшись прекрасным юношей, поступает к Заххаку поваром, всячески угождает ему и в конце концов просит, в качестве вознаграждения, поцеловать Заххака в плечи. После поцелуя у Заххака на плечах вырастают две черные змеи. Избавиться от них невозможно: на месте отрубленной змеи тут же появляется новая. Тогда Ахриман приходит к Заххаку в образе врача и дает ему совет кормить змей человеческим мозгом, надеясь таким образом истребить людей на земле. Далее, когда иранцы провозглашают Заххака царем вместо изгнанного Джемшида, он царствует над Ираном тысячу лет, совершая злодеяния, в том числе ежедневно скармливая двух людей змеям на своих плечах. Он убивает и самого Джемшида, и его потомков. Спастись удается лишь Феридуну, правнуку Джемшида, отданному матерью пустыннику и выращенному в лесах Эльбурса. Именно Феридун, вернувшись в 16 лет и узнав от матери о своем происхождении, побеждает Заххака и оставляет его прикованным к скале в глубокой пещере Демавенда.

Таким образом, неправедный царь из езидской легенды, чья история уложилась в несколько предложений, обнаруживает детальное сходство с тираном-Заххаком из иранского эпоса. Помимо прочего, двух персонажей объединяет даже такая, на первый взгляд, незначительная деталь, как подчеркнуто продолжительное правление. В случае с Заххаком это - тысяча лет, а в случае с царем из езидской легенды - несколько поколений потомков беглецов, нашедших укрытие в горах Ездистана и сформировавших езидский народ.

Интересно, что данный сюжет не отражен ни в одной из версий «Шахнамэ» на курманджи, записанных в Армении ${ }^{16}$ и представляет собой отдельное сказание вне контекста эпоса.

15 A. Avdal, Ezdi k'rderi havatalik'nero, Yerevan 2006, p. 18.

${ }^{16}$ См., например, Rustam-Zal: Zhoghovrdakan vep, [in:] Azgagrakan handes, 1901; S. Haykuni, Rostam Zal, [in:] Eminean Azgagrakan Handēs, vol. 5, Vagharshapat 1904; G. Srvanjtean, Salmann u Rostamn, [in:] Hamov-hotov, Tiflis 1904 и проч.; см. также V. Arakelova, 'Shahnameh'in the Kurdish 
И, наконец, пожалуй, самое существенное во всей этой истории - уникальное использование термина «Ездистан», абсолютно не типичного для езидского фольклора. Указывая на среду своего обитания, езиды прекрасно обходились термином «эздихана», обозначая им и собственно езидскую общину, и территорию, на которой она живет - так называемый walatē ēzdīy $\bar{a}$, «край езидов». Так откуда же взялся «Ездистан»? И почему вообще избежавшие казни и спасшиеся в горах молодые люди стали, согласно легенде, основой именно езидской общины в фольклорной истории, вырванной из контекста иранского эпоса?

Для прояснения данного вопроса необходимо еще раз обратиться к классической версии «Шахнамэ», в которой избежавшие казни и ушедшие в горы молодые люди образуют племя курдов (kurdān). В эпосе речь идет, безусловно, не об этнониме, а о социальном термине «курд», обозначающем любых кочевников-скотоводов. ${ }^{17}$ Тем не менее, начиная с конца 19 века, эта деталь, наряду с другими идеологическими мифологемами, использовалась в зарождавшихся курдских националистических кругах для искусственной архаизации конструируемого этноса, ${ }^{18}$ в частности, для обоснования ряда легендарных версий курдского этногенеза, призванных доказать древность курдов и их исконность на территориях обитания. Именно подобная актуализация курдской идентичности могла породить параллельный езидский контрмиф, подчеркивающий собственную, некурдскую, самобытность и отмежевание от курдской среды, с которой езидов зачастую огульно отождествляли. Вопрос этот был довольно актуальным в среде езидов Армении - в большинстве своем выходцев из исторической Западной Армении - которые, с одной стороны, еще сохраняли живую память о геноциде в Османской империи и гонениях в том числе со стороны курдов, с другой же - сталкивались с игнорированием собственной идентичности со стороны государства и фигурировали как курды во всех советских переписях населения вплоть до 1989 г. ${ }^{19}$

В таком случае виртуальный термин «Ездистан» применительно к «стране/земле езидов» мог возникнуть в повествовании ad hoc, как параллель получавшему - на уровне общественного сознания - все большее распространение термину «Курдистан», также изначально не соотносимому с исторической территорией какого-либо государства, но также огульно применяемому к любой территории обитания курдоязычного конгломерата.

Необходимо также учитывать тот факт, что практически весь фольклор на курманджи в Армении был записан исключительно у езидских и, частично,

and Armenian Oral Traditions [Paper read at the International Conference on Iranian Studies, Sydney (Conference Proceedings), 1998], http://english.paniranist.org/famousiranian/shahnamehkurdarmenia. pdf (access: 17.06.2019).

17 T. Malamīr, Kord dar Šāhnāmeh, "Maǰalle-ye Moțāle“ate Irān̄̄” 2008, no. 14; cм. также G. Asatrian, Prolegomena to the Study of the Kurds, "Iran and the Caucasus" 2009, vol. 13, no. 1.

${ }_{18}$ См. например, D.N. MacKenzie, Pseudoprotokurdica, "Bulletin of the School of Oriental and African Studies” 1963, vol. 26, no. 1; G. Asatrian, Prolegomena to the Study...

19 G. Asatrian, V. Arakelova, Ethnic Minorities of Armenia, Yerevan 2002, pp. 7-8. 
у владевших курманджи армянских сказителей-выходцев из исторической Западной Армении. Условно обозначенный как «курдский» исключительно в силу его языковой принадлежности, этот фольклорный массив вполне мог содержать достаточно раннюю собственно езидскую версию «Шахнамэ», в которой анализируемый сюжет был реинтерпретирован в преломлении к езидам задолго до переселения последних в Восточную Армению, а впоследствии переосмыслен как отдельная, не связанная с эпосом легенда о происхождении народа езидов.

\section{Библиография}

Arakelova V., 'Shahnameh' in the Kurdish and Armenian Oral Traditions [Paper read at the International Conference on Iranian Studies, Sydney (Conference Proceedings), 1998], http://english.paniranist.org/famousiranian/shahnamehkurdarmenia. pdf (access: 17.06.2019).

Asatrian G., Foremother of the Yezidis, [in:] Religious Texts in Iranian Languages, eds. F. Vahman, C.V. Pedersen, Copenhagen 2007, pp. 323-328.

Asatrian G., Prolegomena to the Study of the Kurds, "Iran and the Caucasus" 2009, vol. 13 , no. 1 , pp. $1-57$.

Asatrian G., Arakelova V., Ethnic Minorities of Armenia, Yerevan 2002.

Asatrian G., Arakelova V., The Religion of the Peacock Angel: The Yezidis and their Spirit World, Durham 2014.

Avdal A., Ezdi k'rderi havatalik'nerə, Yerevan 2006.

Bittner M., Die heilige Bücher der Jeziden oder Teufelsanbeter (kurdisch und arabisch), Vienna 1913.

Celil O., Celil C., Zargotina Kurda, Yerevan 1978.

Celil O., Celil C., Zargotina Kurda, vol. 2, Moscow 1978.

Giamil S., Monte Singar: Storia di un Popolo Ignoto, Rome 1900.

Guest J., The Yezidis. A Study in Survival, New York 1987.

Haykuni S., Rostam Zal, [in:] Eminean Azgagrakan Handēs, vol. 5, Vagharshapat 1904, pp. 3-13.

Kreyenbroek Ph., Yezidism - Its Background, Observances and Textual Tradition, New York 1995.

Lescot R., Enquête sur les Yesidis de Syrie et du Djebel Sinjār, Beyrut 1938.

MacKenzie D.N., Pseudoprotokurdica, "Bulletin of the School of Oriental and African Studies" 1963, vol. 26, no. 1, pp. 170-173.

Malamir T., Kord dar Šāhnāmeh, "Maǰalle-ye Moțāle‘ate Irānī” 2008, no. 14, pp. 161-174 .

Rustam-Zal: Zhoghovrdakan vep, [in:] Azgagrakan handes, 1901, pp. 205-258.

Sioufi N., Notice sur la sect des yézidis, "Journal Asiatique" 1882, vol. 19, pp. 252-268. Spät E., Shahid bin Jarr, Forefather of the Yezidis and the Gnostic Seed of Seth, "Iran and the Caucasus" 2001, vol. 6, no. 1-2, pp. 27-56.

Srvanjtean G., Salmann u Rostamn, [in:] Hamov-hotov, Tiflis 1904, pp. 222-224.

Tamoyan A., Menk' ezdi enk', Yerevan 2001. 